\title{
La representación del franquismo en la prensa española de la transición a la democracia
}

\author{
Ricardo Zugasti Azagra*
}

Recibido: 19 de julio de 2012 Aprobado: 8 de septiembre de 2012

\begin{abstract}
Resumen
El objeto de este artículo es analizar la presencia de Franco y del franquismo en los editoriales de la prensa diaria española de la transición a la democracia. El estudio presenta dos objetivos principales: por un lado, conocer si el franquismo fue un tema presente en el discurso periodístico de la época; en la misma línea, examinar qué términos se emplearon para definir el franquismo y, en definitiva, qué valoración se plasmó en la prensa acerca de la dictadura y de su principal protagonista; por otro lado, el franquismo era un tema político con la suficiente entidad para que obligase a las distintas cabeceras a definirse en torno a él. Por ello, los resultados contribuyen a la caracterización política de la prensa española en su conjunto durante la transición y, además, a la particular de las principales cabeceras.
\end{abstract}

Palabras clave: Spain; Daily Press; Journalism History; Francoism; transition.

* Este trabajo forma parte del Proyecto de Investigación de la Universidad de Navarra (PIUNA) La prensa y la 'construcción democrática' en la primera etapa de la transición española (1975-1978) financiado por la Universidad de Navarra, y del proyecto de investigación doctoral desarrollado en la Universidad de Navarra Monarquía, prensa y democracia en la transición española: una relación de complicidad (1975-1978), financiado por el Gobierno de Navarra (España).

** Licenciado en Periodismo y doctor en Comunicación por la Universidad de Navarra. Ha sido ayudante y profesor en el Departamento de Comunicación Pública de la misma Universidad y ha impartido docencia en la Facultad de Comunicación del ITSMO - Guatemala. Universidad de San Jorge. Correo electrónico: rzugasti@usj.es. 


\title{
Representation of Franco regime in Spanish Press from Transition to Democracy
}

\begin{abstract}
The objective of this article is to analyze the presence of Franco and Franco regime in editorials of Spanish daily press, from transition to democracy. This study has two main objectives: on one hand to know if Franco regime was a current topic in the journalist speech of the epoch; in the same line, to examine what terms were used to define Franco regime and, definitely, what was the valuation in the press about the dictatorship and its main character; on the other hand, Franco regime was a political issue with enough identity to oblige different leaders to define themselves around it. Consequently, the results contribute to political characterization of Spanish press as a whole during transition and also to the particular characterization of the main leaders.
\end{abstract}

Key words: Spain, daily press, history of journalism, Franco regime, transition 


\section{Introducción}

Las obras acerca de la prensa española durante la transición a la democracia son numerosas y abarcan desde trabajos sobre la historia del periodismo con una perspectiva cronológica más o menos amplia (Alférez, 1986; Barrera, 1995a; Guillamet, 1996; Seoane, 2007; Castro, 2010), hasta estudios más específicos centrados en alguna publicación concreta (García Escudero, 1984; Sánchez-Tabernero, 1989; Montabes Pereira, 1989; Pàmies, 1993; Olmos, 2002; Seoane y Sueiro, 2004; Nogué y Barrera, 2006), o en el análisis de la cobertura de algún asunto de interés (Zugasti, 2007; García Ortega, 2007). Centrándose en las obras enfocadas al contenido periodístico de la prensa en su conjunto, la representación del franquismo no ha sido directamente estudiada pese a que, en líneas generales, el proceso de la transición consistió en la sustitución de la dictadura franquista por un sistema democrático. Además, la prensa fue durante los años del cambio político un destacado foro de debate político, por lo que una aproximación a su tratamiento del franquismo contribuye a conocer un poco más su papel.

Derivado de lo anterior, el objeto de este trabajo es ofrecer una primera aproximación a la presencia de Franco y del franquismo, entendido este último como sistema político y como período histórico, en la prensa diaria española de la transición a la democracia. La limitada dimensión de este aporte hace, no obstante, recomendable que los resultados aquí mostrados se vean contrastados con obras de mayor envergadura o de diferente enfoque metodológico. Esta dimensión, así como el enfoque particular de este artículo, impiden incluir aquí una caracterización histórica de la naturaleza política y de la trayectoria de la dictadura franquista, un tema historiográficamente muy fértil y que ha sido abordado, además, desde planteamientos ideológicos divergentes. Aproximaciones generales a la figura de Francisco Franco o a su régimen político son, entre otras, las obras de Fusi (1985), Payne (1987), Tusell (1988) y Preston (2005).
El estudio presenta dos objetivos principales. Por un lado, conocer si el franquismo fue un tema presente en el discurso periodístico de la época, en un momento histórico que se abrió precisamente con la muerte de Franco y que consistió en el tránsito hacia una democracia. En la misma línea, resultaba interesante examinar qué términos se emplearon para definir el franquismo y, en definitiva, qué valoración se plasmó en las páginas de la prensa acerca de la dictadura y de su principal protagonista.

Por otro lado, el franquismo era un tema político con la suficiente entidad para que obligase a las distintas cabeceras de prensa a definirse en torno a él. Por ello, los resultados del trabajo podían contribuir a la caracterización política de la prensa española en su conjunto durante la transición y, además, a la particular de las principales cabeceras de la época.

Conviene aclarar desde el comienzo que la prensa no fue, por supuesto, ni el sujeto clave ni el único actor que movió el proceso democratizador: constituyó uno más de los diversos actores personales y colectivos que estuvieron presentes y dinamizaron el proceso de cambio. Sin embargo, dadas sus particulares características, la prensa diaria adquirió una especial fuerza en los años en que la España de la dictadura franquista pasó a convertirse en una democracia constitucional. Esas características propias de la prensa eran: su capacidad de penetración y de resonancia en la opinión ciudadana, y su influencia en las capas altas de la política, la sociedad, la economía y la cultura, que habitualmente presentan un mayor protagonismo decisorio en la vida pública.

Además, la libertad de prensa de que gozaba la prensa escrita en la España de 1975, aun con limitaciones evidentes, había ganado terreno con respecto a la situación existente diez años antes. La nueva Ley de Prensa e Imprenta de 1966, junto con el empuje de algunos periódicos y revistas por ir ampliando los márgenes informativos y editoria- 
les que el Gobierno permitía, habían significado un paso importante hacia el cumplimiento de la labor informativa e interpretativa de la prensa. La muerte de Franco supuso, de hecho, que los periódicos se mostraran más atrevidos y se comportaran como si hubiera una auténtica libertad de prensa (Alférez, 1986; Barrera, 1995).

Al igual que aumentó la libertad de los periódicos, creció el número de títulos nuevos que salían al mercado, precisamente al calor de esos nuevos aires de cambio político. Desde el punto de vista jurídico, la primera medida importante de liberalización de la prensa no llegó hasta el 1 de abril de 1977, en que un decreto derogó los artículos más punitivos de la Ley de Prensa de 1966. El más alto reconocimiento legal de la libertad de información tuvo que esperar a la Constitución de 1978, cuyo artículo 20 expresa solemnemente que "todo español tiene el derecho a comunicar o recibir libremente información veraz por cualquier medio de difusión" (Constitución Española, 1978).

El contexto de la crisis económica internacional, que afectó de lleno a la España de la Transición, fue un factor que repercutió negativamente en el esperado aumento de publicaciones periódicas. El panorama general fue inestable: bastantes de las nuevas iniciativas tuvieron escasa vida y algunos periódicos tradicionales sufrieron serias dificultades para mantenerse, debido a la necesidad de renovación tecnológica, a los altos costes de producción y de personal, a la falta de adecuación ideológica a los nuevos tiempos, y al empuje de algunos nuevos periódicos que se constituyeron en seria competencia de los tradicionales líderes de opinión (Barrera, 1997: 7-46).

Pese a las dificultades, el mayor pluralismo periodístico permitió que la prensa de la transición actuara como un auténtico "parlamento de papel". Se ha acuñado esta expresión "parlamento de papel" para aludir al rol de la prensa en los años del tardofranquismo, principalmente desde la entrada en vigor de la nueva Ley de Prensa e Imprenta en
1966. Al hallarse taponados otros cauces oficiales de debate político, la prensa -que gozaba de una mayor libertad por el nuevo contexto legal- fue el foro donde más abiertamente se difundieron ideas políticas que luego serían moneda común (Montabes Pereira, 1994). Como no hubo Cortes elegidas democráticamente por sufragio universal hasta julio de 1977, la prensa siguió actuando como "parlamento de papel" hasta esa fecha. Y la vida política, lógicamente, se adueñó de los principales contenidos de los periódicos, en cuyas páginas hallaban amplia cabida y cobijo los viejos y los nuevos políticos que "hacían" la transición (Terrón Montero, 1981; Barrera, 1995; Chuliá, 2001).

\section{Metodología}

Se han seleccionado doce diarios como fuente: seis editados en Madrid y de circulación nacional; tres publicados en Barcelona, segundo gran mercado periodístico de España; y otros tres del País Vasco. Junto al inevitable criterio ideológicopolítico para la mayor representatividad posible de la muestra, se ha atendido también a criterios geográficos, dada la presencia de temas como la amnistía y las autonomías, que afectaban de modo muy especial tanto a Cataluña como al País Vasco.

Entre la prensa madrileña, los diarios que habían coexistido con el franquismo se caracterizaban por su perfil conservador, pese a las diferencias: ABC poseía su histórico carácter monárquico (Olmos, 2002), Pueblo era un vespertino gubernamental que había sido durante el franquismo el órgano de los sindicatos verticales (Sánchez Rada, 1996) y Ya era un diario confesional católico, heredero del famoso El Debate (García Escudero, 1984). Ubicado en la extrema derecha estaba El Alcázar, dependiente de la Confederación Nacional de Combatientes liderada por el falangista Girón (Alférez, 1986). Tras la muerte de Franco vieron la luz dos periódicos llamados a dinamizar el panorama periodístico por su novedoso perfil político izquierdista: El País (Seoane y Sueiro, 2004) y Diario 16 (Andía, 2009). 
El mercado barcelonés de prensa estaba dominado por el veterano La Vanguardia, de trayectoria y talante conservadores (Nogué y Barrera, 2006). El Correo Catalán se caracterizó desde el tardofranquismo por mantener un discurso político más audaz y progresista que el de otras cabeceras coetáneas (Nogué y Barrera, 2006). La gran novedad fue Avui, diario nacido en 1976, con una marcada vocación catalanista de izquierdas (Solà y Dachs, 1978).

En cuanto a la prensa vasca, el liderazgo lo ostentaban El Correo Español (Sánchez-Tabernero, 1989) y La Gaceta del Norte (Lerchundi, 1985), dos diarios conservadores, especialmente el último, y donde el nacionalismo vasco encontraba difícilmente cabida. La primera cabecera representativa de este nacionalismo fue Deia, creado en 1977 con un ideario próximo al Partido Nacionalista Vasco (Bezunartea, 1988).

La técnica de investigación empleada fue el análisis de contenido cualitativo. A diferencia del cuantitativo, centrado fundamentalmente en las cantidades reflejadas en una cobertura y en la frecuencia con la que aparecen mencionados unos determinados elementos o aspectos, la metodología cualitativa permite en mayor grado y con mayor facilidad tanto captar los significados, los matices y los distintos énfasis de cada información y cobertura, como mostrar las argumentaciones de los artículos con sus diversos propósitos y connotaciones. En una investigación como la presente, interesaba garantizar la identificación y conocimiento de los matices, de los detalles que diferenciaron las coberturas de cada medio y, en concreto, las argumentaciones ofrecidas por estos en cada caso. Además, y en relación con lo anterior, la metodología cualitativa se muestra más flexible para abordar el estudio de temas que pueden resultar complejos por sus múltiples aristas o porque puedan presentar variaciones a lo largo del período estudiado. Por último, una investigación resultante del tipo de análisis empleado presenta una ventaja innegable: permite leer los textos analizados, si bien tan solo se reproduce aquella parte considerada sustancial y pertinente en cada caso. Es decir, no reduce los textos periodísticos a números, evitando así desvirtuar su propia naturaleza y descontextualizar los significados discursivos (Jensen y Jankowski, 1993; Lindlof, 1995; Altheide, 1996).

En concreto, se analizan los editoriales que estos diarios publicaron con motivo de veintiún acontecimientos históricos de la transición referidos a tres ámbitos principales en que se operó la democratización: la recuperación de las libertades públicas, la obtención de la amnistía, y la configuración de las primeras autonomías. Para la delimitación cronológica de los acontecimientos hemos seguido un criterio básicamente político-institucional, es decir, el período que va desde la proclamación del rey Juan Carlos I el 22 de noviembre de 1975 hasta la aprobación del referéndum constitucional el 6 de diciembre de 1978. La tabla 1 muestra los acontecimientos seleccionados.

Los editoriales fueron fácilmente identificables, ya que solían estar encabezados por este nombre. Si no era así, consideramos como editoriales los artículos esencialmente interpretativos sin firma o firmados expresamente por el periódico. Pretendiendo ofrecer al lector únicamente un elemento básico de comprensión y dejando a un lado el debate académico sobre tipología y géneros, el editorial presentaba varias ventajas de distinto tipo: su más fácil acotamiento, dado el extenso período que se trataba de cubrir; su carácter de pieza doctrinal básica y "portavoz de la línea ideológica de la publicación donde se inserta" (Armañanazas Y Díaz Noci, 1996, p. 93); y el mayor acceso que proporciona a las claves discursivas y argumentales del diario a través del decurso histórico. Una completa revisión de las tipologías de textos periodísticos está en Vilarnovo y Sánchez (1994, p. 133-165). 
Tabla 1. Acontecimientos analizados

\section{Libertad:}

- Discurso del Rey ante las Cortes (22-XI-1975)

- Discurso del Rey ante el Congreso de los Estados Unidos (2-VI-1976)

- Discurso del Rey ante las primeras Cortes democráticas (22-VII 1977)

- Discurso de Suárez en las Cortes: defensa del derecho de asociación política (9-VI-1976)

- Programa de gobierno del ejecutivo presidido por Suárez (16-VII 1976)

- Aprobación en las Cortes de la Ley para la Reforma Política (18-XI-1976)

- Aprobación en referéndum de la Ley para la Reforma Política (15-XII-1976)

- "Semana sangrienta" (23 al 30-I-1977)

- Elecciones generales (15-VI-1977)

- Aprobación en referéndum de la Constitución (6-XII-1978)

\section{Amnistía:}

- Primer indulto del Rey (25-XI-1975)

- Amnistía inicial del gobierno Suárez (30-VII-1976)

- Segunda amnistía del gobierno Suárez (14-III-1976)

- Amnistía general de las Cortes (14-X-1977)

\section{Autonomía:}

- Entrevistas de Tarradellas con Suárez y el Rey (27-VI-1977)

- Asambleas de parlamentarios en Euskadi y Cataluña (26-VI-1977)

- Diada multitudinaria en Barcelona (11-IX-1977)

- Restablecimiento de la Generalitat (29-IX-1977)

- Regreso de Tarradellas a Barcelona (23-X-1977)

- Vuelta del exilio de Manuel Irujo (25-III-1977)

- Constitución del Consejo Genera 1 Vasco (31-XII-1977)

\section{Entre la democracia orgánica y la dictadura}

Las alusiones a Francisco Franco fueron numerosas en los editoriales publicados con motivo de la proclamación de don Juan Carlos de Borbón como Rey de España el 22 de noviembre de 1975.
No en vano, Franco había muerto tan solo dos días antes. Todos los diarios analizados plasmaron una imagen positiva del general y de su Régimen, institucionalmente todavía en vigor. Sin embargo, tras ese consenso en la aprobación de la figura y obra del fallecido Jefe del Estado, es posible distinguir alguna diferencia en los discursos de los periódicos. 
Así, el diario que buscó marcar una continuidad entre Franco y su sucesor fue El Alcázar: "El pueblo ha sido unánime al improvisar su respuesta sobre lo que esperaba del Rey nuevo: continuar y mejorar la obra de Franco. ¿Cabe más tentador y comprometido programa?". No olvidó el mismo editorial lanzar una andanada contra la clase política, tan denostada por el diario editado por Dyrsa:

Hay dos hallazgos aleccionadores en esta hora del duelo y de esperanza: el pueblo se entendió con Franco durante cuarenta años y Franco se entendió con el pueblo, sin que la mayoría de los políticos, y más aún los recientes, se apercibieran de que estaban fuera del escenario, trastocados de actores en tramoyistas (El Alcázar, 1975, 24 de noviembre, p. 3).

El resto de cabeceras mostraron que el franquismo era el punto de origen y fuente de legitimidad de la nueva Monarquía, pero hicieron ver al mismo tiempo que el camino político del Rey recién instaurado no podía seguir el rumbo de la continuidad. La Vanguardia (1975, 23 de noviembre) afirmó que Juan Carlos I era "el sucesor de Franco" y continuó:

Tras el fenómeno históricamente irrepetible de Franco, el rey Don Juan Carlos I representa una voluntad de renovación: al frente de la nación, nos encontramos ahora con un árbitro y coordinador de funciones que vigilará la acción de las instituciones y garantizará que los derechos de los ciudadanos sean respetados y protegidos (p. 7).

La misma idea latía en el texto de un editorial del diario bilbaíno El Correo Español (1975, 24 de noviembre) que, tras indicar que el Rey debería acometer cambios, indicó que estos iban a ser posibles "a partir de la herencia de paz y de prosperidad que recibimos, como precioso legado, del Caudillo Franco" (contraportada). El diario madrileño Ya (1975, 22 de noviembre) marcó también las diferencias entre el período que terminaba y el que comenzaba:
Pero adviértase que la Monarquía no podrá ser un franquismo sin Franco, ni debería serlo aunque pudiera. Solo intentarlo sería la condenación de la Monarquía y de la conciliación que debe conseguir. Las circunstancias son diferentes y exigen fórmulas y actitudes nuevas (p. 7).

Las multitudes que esperaron largas colas para desfilar ante el cadáver de Franco sirvieron al diario de la Editorial Católica para mostrar que ese apoyo popular con que todavía contaba el difunto dictador podía servir al Rey, una opinión que no obstante dejaba entrever la duda acerca del apoyo del pueblo español hacia Juan Carlos I. Era en definitiva un intento por transferir al Rey parte de la legitimidad carismática del anterior Jefe del Estado, a quien definía como "forjador de la paz":

El extraordinario plebiscito de adhesión y afecto a Franco con ocasión de su muerte se presta a consideraciones políticas que pueden alterar muchos esquemas vueltos de espaldas a esa impresionante realidad popular. En esas masas tiene don Juan Carlos su base inmediata de apoyo; su éxito será ampliar esa base hasta que en ella esté prácticamente todo el país (Ya, 1975, 24 de noviembre, p. 7).

Otro editorial del mismo diario, significativamente titulado "Las colas, un factor de primera magnitud", incidía en el mismo argumento:

El postrer servicio de Franco al futuro ha sido la apelación al pueblo español que hace en su testamento político para que se agrupe en torno al Rey como lo hizo con él. Podríamos añadir que, aun después de muerto, Franco ha ganado su última batalla, que ha sido ofrecer al Rey las masas que en espontáneo, sincero, conmovedor plebiscito han acudido a darle su fervoroso adiós (Ya, 1975, 25 de noviembre, p. 7).

ABC (1975, 22 de noviembre) sacó también a relucir la petición de Franco en su testamento 
político, buscando del mismo modo un refuerzo del apoyo popular a Juan Carlos I a través de los fieles a Franco:

Muy bien saben los últimos de Franco que su mandato permanente, su última orden, ha sido la de agruparse lealmente alrededor del Rey. Atengámonos todos a lo que el Rey proponga, a sus altas indicaciones, que no podrán tener otro norte sino el mantenimiento de la paz, la convivencia y el diálogo (p. 3).

Unos meses después, una de las más tempranas y rotundas críticas contra el franquismo provino del entonces recién nacido Avui (1976, 8 de junio), que aprovechó la apertura internacional que para España supuso el viaje de los Reyes a los Estados Unidos (Barrera, La Porte y Pellicer, 1999) para contraponerlo con "un Estado que ha representado durante tantos años la excepción, el ghetto de un sistema político marginado" (p. 1).

El discurso de Adolfo Suárez, todavía ministro secretario general del Movimiento, ante las Cortes defendiendo la Ley de Asociaciones Políticas en junio de 1976 provocó que dos periódicos con un perfil político diametralmente opuesto sacaran a relucir el franquismo. El Alcázar (1976, 11 de junio) interpretó la maniobra política como un intento traicionero de los políticos reformistas que, dejando a un lado la lealtad, buscaban dinamitar desde dentro un Régimen digno de mantenerse:

Pero lo más peregrino, por no decir lo más vergonzoso, no es que se quiera destruir a la muerte de Franco el sistema que con tanto cariño y previsión impulsó a crear para garantizar la continuidad de la gran obra de reconstrucción realizada ('todo queda atado y bien atado'). Eso ya hace tiempo que lo vienen intentando comunistas, separatistas, plutócratas resentidos y terroristas de diversas tendencias. Lo vergonzoso es que haya personas que un día, con muestras de lealtad a Franco que llegaban al servilismo, escalaron posiciones desde las que ahora intentan traicionar, tras su muerte, lo que ayudaron a construir cuando vivía (p. 2).

Bien distinta fue la visión de El País (1976, 11 de junio), el nuevo diario que llevaba en la calle poco más de un mes. Para este medio, los votos negativos en las Cortes a la Ley de Asociaciones Políticas provenían de "los líderes de la derecha franquista" que "temen perder lo que tienen". Indicaba, además, que existían en España unas condiciones difíciles para la creación y funcionamiento de los partidos políticos "por obra y gracia de la llamada democracia orgánica" (p. 8).

El programa del Gobierno Suárez se presentó a mediados de julio de 1976 y en él se prometió la consecución de un sistema político democrático y una amnistía para los presos encarcelados por motivos políticos o de opinión. Un editorial del vespertino Pueblo (1976, 17 de julio) manejó un discurso similar al visto en otras cabeceras con motivo de la proclamación del Rey, esto es, valorar positivamente la obra de Franco, pero indicando que era hora de pasar página:

Casi medio siglo después, se trata de que todos los problemas del país, y la herencia enorme, pero ahora inerte de la era de Franco, se pongan de nuevo al servicio de un gran ideal colectivo de vida que se constituya en torno a la libertad y a la democracia (p. 3).

El 30 de julio llegó la amnistía, todavía parcial, lo que hizo que algunos periódicos volvieran a aludir al franquismo en sus editoriales. El País (1976, 5 de agosto) solicitó una amnistía más amplia en un comentario que suponía una dura crítica implícita al franquismo:

Los planteamientos subversivos que promueven la destrucción del adversario son siempre condenables. Pero no habría que olvidar los motivos de persecución, de humillación o de desesperación que en 
algunos casos dieron origen a la rebeldía armada. Estas circunstancias deberían reconsiderarse a la hora de aplicar el decreto de amnistía (p. 7).

En esta línea y con motivo de la ampliación de esta amnistía en 1977, Diario 16 (1977, 12 de marzo), refiriéndose al País Vasco, habló de "los errores de cuarenta años de represión institucionalizada" (p. 4).

Por el contrario, El Alcázar (1976, 2 de agosto) volvió a hacer gala de su papel como defensor del franquismo al interpretar la amnistía como una concesión a las fuerzas opositoras que suponía un paso más en el "desguace del Régimen" y en la "liquidación del Estado Nacional" (p. 2). En otro editorial, El Alcázar (1976, 2 de agosto) hizo un repaso a todas las medidas de gracia adoptadas por Franco para decir que también este promovió la reconciliación, si bien puso reparos a la reacción de los favorecidos por la reciente amnistía: "Quienes se han hecho beneficiarios de ella son los que tienen la palabra. Y tememos que esa palabra les califique definitivamente (p. 2)".

La aprobación, primero en las Cortes y después en referéndum, de la Ley para la Reforma Política constituyó un hito en el proceso de transición y fueron habituales las referencias al franquismo ante un hecho que suponía la aprobación a través de la vía reformista de un sistema político democrático para España. Excepción hecha de El Alcázar, el resto de periódicos valoraron favorablemente la aprobación de la ley que abría la puerta a la celebración de unas elecciones libres. El diario editado por la Confederación Nacional de Combatientes reiteró sus acusaciones de traición a los políticos reformistas y dibujó la democracia liberal como una suerte de caja de Pandora que se llevaría por delante los logros alcanzados durante el franquismo:

Quisiéramos equivocarnos. Pero desde hoy, el pueblo español va a tener que saturarse de las más grandilocuentes promesas de libertad, en tanto que, parejamente, irá comprobando en su propio entorno familiar, cómo se le merman aquellas libertades concretas conquistadas con sacrificio y esfuerzo, sí, pero con ilusión, durante los siete lustros de la paz de Franco.

En el Parlamento español renace de nuevo la democracia liberal. iDios salve a España! (El Alcázar, 1976, 19 de noviembre, p. 2).

Aquellos periódicos que apostaron por un sistema democrático presentaron, no obstante, diferencias en cuanto a la valoración que ofrecieron del franquismo. Por una parte, hubo diarios que pusieron el acento en el carácter reformista de la ley democratizadora y que se refirieron al período franquista y a su forjador en términos laudatorios o, cuando menos, comprensivos. Así, ABC (1976, 15 de diciembre) habló del franquismo como de "un régimen de autoridad" que merecía "grandes reconocimientos" (p. 3). El diario gubernamental Pueblo (1976, 18 de noviembre) definió la España democrática que se intentaba conseguir como "una herencia de Franco" (p. 3). El vespertino sindical intentó en otro editorial contrarrestar los intentos de los inmovilistas por atribuirse la legitimidad franquista para evitar la reforma y esbozó una imagen de Franco como estadista al margen de partidismos que no dejaba de ser positiva:

¿De qué ingleses de hoy es Cromwell, de qué partido americano es Washington, de qué franceses Napoleón, de qué italianos Cavour, de qué grupo político sudamericano es Bolívar? Convertir a Franco en símbolo de unos españoles contra otros cuarenta años después de la guerra sería por lo menos un contrasentido, porque toda su obra consistió -la historia dirá si esto fue plenamente logrado- en superar las diferencias políticas. Lo que no vale es reservarse a los grandes hombres, y adjudicárselos como patrimonio para grupos o partidos (Pueblo, 1976, 17 de noviembre, p. 3). 
El Correo Español (1976, 16 de noviembre) utilizó una expresión empleada por el propio Régimen para referirse al franquismo: "A un año de la muerte de Franco se trata de sustituir la democracia orgánica por la inorgánica de partidos" (p. 19). El rotativo bilbaíno mostró asimismo sus deseos de que en el proceso hacia la democracia se mantuviera la paz, que constituía "el más precioso legado del Régimen de Franco" (El Correo Español, 1976, 15 de noviembre, p. 26). Pueblo (1976, 16 de diciembre) recogió el mismo término eufemístico:

Se ha pasado de la democracia orgánica -a la que se comparó hace días en las Cortes con la legendaria yegua de Rolando, que era hermosísima pero que estaba muerta- a la democracia inorgánica, tal como se practica en todas las naciones occidentales (p. 3).

El concepto de democracia orgánica fue empleado asimismo por el también vasco La Gaceta del Norte (1976, 20 de noviembre), que además incluyó una alabanza de los logros del franquismo:

La democracia orgánica, por encima de todas las objeciones que pueden hacérsele, concluyó su trayectoria con un saldo notablemente favorable de realizaciones. Faltaba acompasar esas realizaciones a un tiempo nuevo en el que, precisamente por madura y desarrollada, exigía adentrarse de lleno en la democracia (p. 28).

De una manera más mesurada, el diario Ya (1976, 14 de diciembre) se refirió al franquismo como una "autocracia personal" donde era "todopoderoso un poder carismático" (p. 7). Evitando también el elogio excesivo a un sistema que calificó como "régimen autoritario" (La Vanguardia, 1976, 14 de diciembre, p. 7), La Vanguardia (1976, 18 de noviembre) sostuvo, no obstante, que la puerta de la democracia la dejó "entreabierta el propio Franco" (p. 7), e hizo equilibrios sobre una perífrasis para mostrar el carácter no democrático del franquismo: "Se trata, sí, de organizar la convivencia a partir de fórmulas que durante cuarenta años quedaron congeladas por haber asumido todos los poderes la figura militar más elevada después de la victoria en la guerra civil" (La Vanguardia, 1976, 17 de noviembre, p. 7).

Por otra parte, hubo periódicos que fueron críticos con el franquismo y que lo calificaron utilizando un término que no encontró cabida en las páginas de los diarios antes vistos: dictadura. Así, Diario 16 (1976, 14 de diciembre) propugnó el voto afirmativo explicándolo así: "El referéndum es un trámite, se mueve todavía dentro del orden franquista. Pero [...] después de él estaremos un poco más cerca de la democracia y seguramente más lejos de la dictadura" (p. 4). Con ocasión de la discusión en Cortes de la Ley para la Reforma Política, Diario 16 asoció con la dictadura expresiones como "rígido corsé" (1977, 17 de noviembre, p. 4), "imposición dogmática", "sometimiento" o "dedocracia insigne" (1977, 19 de noviembre, p. 4).

Para El País (1976, 19 de noviembre), la aprobación en las Cortes de la Ley para la Reforma Política suponía "el final de las instituciones de la dictadura y el comienzo de la democracia" (p. 6). En similares términos se expresó El Correo Catalán (1976, 16 de noviembre), para el que el trámite por las Cortes era la transición "de un sistema dictatorial a un sistema democrático" (p. 3). Más duro se mostró El País (1976, 14 de diciembre) con motivo del referéndum al calificar a quienes propugnaban el voto negativo como "los nostálgicos del totalitarismo" (p. 8). Por su parte, el periódico barcelonés aprovechó el alto porcentaje de abstención en el País Vasco para criticar abiertamente el centralismo franquista:

A este respecto, el ejemplo más significativo es el del País Vasco, víctima de la peor de las políticas del franquismo en cuanto a las nacionalidades y regiones, aun teniendo en cuenta que a este respecto en ningún caso fue acertada (El Correo Catalán, 1976, 17 de diciembre, p. 3).

La oleada de secuestros y de atentados terroristas conocida como la "semana sangrienta", que 
asoló Madrid a finales de enero de 1977, consiguió que la prensa de distintas tendencias mostrara su unidad frente al terrorismo y a los intentos desestabilizadores. El fruto más destacado fue la publicación de "Por la unidad de todos" un editorial conjunto de la prensa madrileña publicado incluso en las páginas de El Alcázar (Zugasti, 2008). Pese a este consenso periodístico, El País y ABC mantuvieron una breve polémica precisamente por la valoración del franquismo. El diario de Prisa escribió que las primeras acciones terroristas se debían al "intento desesperado de grupos detentadores de amplias parcelas de poder por mantener estas, aun después de la muerte del general Franco" y terminaba el editorial afirmando que:

Lo verdaderamente importante, por el momento, es llegar a las elecciones en condiciones de que estas sean viables. Luego, el Estado que de ellas surja deberá empezar a barrer tanta basura como ha quedado (El País, 1977, 25 de enero, p. 8).

La respuesta airada de $\mathrm{ABC}$ (1977, 26 de enero) no se hizo esperar. Después de afirmar que la acusación de El País era "gravísima, absolutamente infundada, y notoriamente falsa", contradijo la visión negativa del franquismo:

¿Significa esto que el Estado de las Leyes Fundamentales en vigor no ha hecho sino acumular basura sobre el territorio nacional? Tal afirmación sería inadmisible. Nada humano es perfecto; pero uno de los Estados cuya gestión arroja un saldo más positivo en la Historia contemporánea de España es, sin duda alguna, el todavía vigente, protagonista de la revolución industrial en España, y autor de la reforma social más avanzada, extensa y profunda que ha conocido el país (p. 2).

\section{La presencia del franquismo disminuye tras el triunfo de la reforma}

Los diarios que hicieron alusiones positivas al franquismo, y en especial a sus logros, pero mostrando esta realidad como algo compatible con una nueva y deseable España democrática fueron diluyendo las referencias positivas al régimen franquista conforme se avanzaba en la democratización.

Pese a que es posible encontrar en ellos alguna crítica a políticas concretas del franquismo, como es el caso de ABC (1978, 5 de enero, p. 2) con la política seguida hacia la cuestión regional, las críticas editoriales a la totalidad del franquismo en estos diarios fueron inexistentes. Quizá la única excepción sea un postrero editorial de Pueblo (1978, 7 de diciembre) donde se afirmaba que, debido al mayoritario sí a la Constitución en el referéndum, "va a ser muy difícil mantener el equívoco de la dictadura carismática y de tantos nostálgicos que sueñan todavía con esta forma de gobierno, sobre una presunta indiferencia o inhibición política del pueblo español" (p. 3).

Una mención aparte merece La Vanguardia, que experimentó un giro en su discurso político hacia un catalanismo más acusado que se vio acompañado por la aparición de críticas al régimen franquista, antes inexistentes en dicho periódico. Así, hacia los meses de septiembre y octubre de 1977, en el contexto del restablecimiento de la Generalitat, el rotativo catalán va a calificar el franquismo como "dictadura centralista" (La Vanguardia, 1977, 11 de septiembre, p. 5), hablará de ella metafóricamente como un "penoso desierto" (La Vanguardia, 1977, 25 de octubre, p. 9), y se referirá, en relación a Cataluña, a los "cuarenta años de persecución incivil a sus valores singulares e indestructibles" (La Vanguardia, 1977, 30 de septiembre, p. 8).

Por su parte, aquellos diarios que habían ofrecido referencias negativas al franquismo en su conjunto continuaron con ellas. El catalanista Avui (1977, 29 de septiembre) lo calificó con motivo del restablecimiento de la Generalitat como "un poder históricamente opresor, mezquino y desconfiado" (p. 1). En el contexto de las primeras elecciones 
democráticas, el nacionalista vasco Deia (1977, 17 de junio) afirmó que "durante muchísimos años hemos sido gobernados a contrapelo de lo que realmente queríamos", y definió el resultado electoral como "voto de censura al franquismo" (p. 3). El Correo Catalán volvió a definir el franquismo como "dictadura personal" tras la apertura de las Cortes democráticas. Por su dureza reprobatoria del franquismo destacó también un editorial de El País en el que se pedía el voto afirmativo en el referéndum constitucional (1978, 5 de diciembre):

Y así se ha de certificar el cerrojazo histórico a una dictadura que mantuvo durante cuarenta años a los españoles bajo la presión del miedo y de la injusticia, contribuyó al empequeñecimiento nacional y aumentó nuestras dependencias estratégicas y económicas de las grandes potencias extranjeras. Ese régimen, hoy añorado por sus más directos beneficiarios, es el paradigma de lo que nunca debe ser un sistema político que respete al hombre y a la sociedad (p. 11).

Por último, El Alcázar no se rindió y continuó enarbolando incansablemente la bandera de la defensa del franquismo frente al proceso de democratización. De manera rotunda fijó su postura tras la celebración de las primeras elecciones democráticas:

El carnaval ha terminado. Deseamos sinceramente a nuestro pueblo que no empiece ahora la cuaresma. Una cuaresma que ya se hacía sentir, aunque quedará disimulada por el cúmulo de bienes almacenados durante el denostado 'franquismo' (El Alcázar, 1977, 17 de junio, p. 2).

Especialmente intensos fueron el ataque del diario ultraderechista contra el proyecto de Constitución, y la búsqueda del voto negativo en el referéndum con la esperanza puesta en evitar in extremis una derogación explícita de las Leyes Fundamentales. "España derrotada en el
Parlamento" (El Alcázar, 1978, 1 de noviembre, p. 1) llegó a titular en portada a grandes caracteres después de la ratificación del texto constitucional por las Cortes. Un editorial publicado a finales de diciembre, en el que hacía una interesada interpretación de los resultados del referéndum, puede servir de ejemplo para ilustrar su posición frente a la Carta Magna:

Se ha dicho que la Constitución es de todos y para todos, aunque en rigor, y a juzgar por las cifras oficiales del referéndum, un cuarenta por ciento del censo nacional haya permanecido de espaldas a su letra y espíritu (El Alcázar, 1978, 28 de diciembre, p. 1).

\section{A modo de conclusión}

Del trabajo se desprende que Franco y el franquismo estuvieron presentes en los discursos editoriales de la prensa. Tuvieron una aparición más habitual durante los primeros compases de la transición, una presencia que fue diluyéndose en buena parte de los periódicos conforme el proceso de democratización avanzaba. Los diarios con más larga tradición y talante conservador fueron precisamente los que, con la excepción de El Alcázar, se desprendieron progresivamente de esas alusiones, algo que puede considerarse parte de su propio proceso de "conversión" a la democracia. Los diarios que aparecieron al albur del nuevo contexto político, poseedores de un discurso político más situado a la izquierda, mantuvieron las alusiones al franquismo, pero las utilizaron para caracterizarlo negativamente y restarle legitimidad.

El Alcázar fue el único periódico que, en sintonía con su perfil ultraderechista y su aversión por el sistema político democrático, mantuvo una presencia abundante e insistente a favor del franquismo y de Franco. Fue el único rotativo que se opuso frontalmente a las reformas democratizadoras y apostó por mantener vigentes las esencias políticas del Régimen del 18 de Julio. 
Otros diarios de larga vida y ubicados políticamente a la derecha (ABC, Ya, El Correo Español, La Gaceta del Norte, Pueblo) apostaron, con mayor o menor énfasis, por la consecución de un sistema democrático para España, en la línea reformista que desde el Gobierno y la Corona se estaba impulsando. Pese a su apuesta a favor de un régimen democrático, estos periódicos mantuvieron una actitud cuando menos respetuosa hacia el franquismo y eludieron mayoritariamente definir el Régimen como dictadura. Caso aparte constituyó el giro de La Vanguardia, que comenzó compartiendo perfil político con estos diarios y terminó emitiendo duros juicios sobre el franquismo, en consonancia con la potenciación del elemento catalanista en sus páginas.

Los periódicos que vieron la luz durante la transición aportaron al panorama periodístico español perfiles políticos hasta entonces prácticamente inexistentes y que sintonizaban con la oposición: más ubicados a la izquierda y/o caracterizados por su nacionalismo catalán o vasco. Estos diarios (Avui, El País, Diario 16, Deia) más El Correo Catalán no dudaron en calificar el franquismo como dictadura, y sus páginas albergaron un discurso netamente crítico, basado en la carencia de legimitidad democrática.

No obstante y a pesar de las diferencias ideológicas de los principales diarios analizados, se percibe un interés de la prensa por centrarse en los puntos de encuentro más que en los de la lógica divergencia. La prensa fue así un actor cuya conducta y cuyos mensajes se basaron en una razonable moderación, y no en una demagógica agitación. Esto no fue obstáculo para que algunos periódicos presionaran, con su política informativa y editorial, a favor de afianzar los derechos individuales y las libertades públicas.

Las representaciones del pasado histórico inmediato como el franquismo no fueron temas tabú para la prensa de la transición, y los periódicos hablaron de ese pasado de acuerdo con sus prin- cipios ideológicos y sus estrategias políticas, pero no los utilizaron como un instrumento de lucha política de unos contra otros. Aquí se produjo un evidente paralelismo con el comportamiento de los políticos durante los años del cambio político. No hacer del pasado un arma que pudiera poner en peligro la reconciliación de los españoles tuvo una razón de ser política: fue parte nuclear del pacto entre los sectores procedentes del franquismo y los de la oposición democrática.

\section{Bibliografía}

Alférez, A. (1986). Cuarto poder en España. La prensa desde la Ley Fraga 1966. Barcelona: Plaza E Janés.

Altheide, D. L. (1996). Qualitative Media Analysis. Thousand Oaks: Sage.

Andía, L. A. (2009). El primer Diario 16 (1976 1980). Pamplona: Universidad de Navarra, tesis doctoral inédita.

Armañanzas, E., y Díaz Noci, J. (1996). Periodismo y argumentación. Géneros de opinión. Bilbao: Servicio editorial de la Universidad del País Vasco.

Barrera, C: (1995a). Sin Mordaza. Veinte años de prensa en democracia. Madrid: Temas de Hoy.

Barrera, C. (1995b). Periodismo y franquismo. De la censura a la apertura. Ediciones Internacionales Universitarias: Barcelona.

Barrera, C. (1997). Poder político, empresa periodística y profesionales de los medios en la transición española a la democracia. Comunicación y Sociedad, vol. X, núm. 2, pp. 7-46.

Barrera, C., La Porte, M. T., y Pellicer, S. (1999). Diplomacia, marketing político y opinión pública en el viaje de los reyes a los Estados Unidos en junio de 1976. Comunicación y Estudios Universitarios, núm. 9, pp. $171-183$.

Bezunartea, O. (1988). Noticias e ideología profesional. La prensa vasca en la transición política. Ediciones Deusto: Bilbao. 
Castro, C. (2010). La prensa en la transición española. Alianza: Madrid.

Chuliá, E. (2001). El poder y la palabra. Prensa y poder político en las dictaduras. El régimen de Franco ante la prensa y el periodismo. Biblioteca Nueva/UNED: Madrid.

Fusi, J. P. (1985). Franco. Autoritarismo y poder personal. El País: Madrid.

García Escudero, J. M. (1984). Ya. Medio siglo de historia. 1935-1985. BAC: Madrid.

García Ortega, C. (2007). La transición en Navarra a través de la prensa: el periodo de los debates constitucionales. Pamplona: Universidad de Navarra, tesis doctoral inédita.

Guillamet, J. (1996). Premsa, franquisme i autonomia. Crònica catalana de mig segle llarg (1939-1995). Flor del vent: Barcelona.

Jensen, K. B., y Jankowski, N. W. (1993). Metodologías cualitativas de investigación en comunicación de masas. Bosch: Barcelona.

Lerchundi, A. (1985). La Gaceta del Norte. Sus ochenta y tres años de vida. Servicio Editorial de la Universidad del País Vasco: Bilbao.

Lindlof, T. R. (1995). Qualitative Communication Research Methods. Sage: Thousand Oaks.

Montabes Pereira, J. (1989). La prensa del Estado durante la transición política española. CIS: Madrid.

Montabes Pereira, J. (1994). Los parlamentos de papel en el caso español. En C. H. Filgueira y D. Nohlen (comps.), Prensa y transición democrática. Experiencias recientes en Europa y América Latina. Iberoamericana: Madrid, pp. 42-67.

Nogué, A., y Barrera, C. (2006). La Vanguardia, del franquismo a la democracia. Madrid: Fragua.

Olmos, V. (2002). Historia del ABC. 100 años clave en la historia de España. Barcelona: Plaza E Janés.
Pàmies, O. (1993). El Grup Mundo. Pecats i penitències d'una premsa de transició. Barcelona: Col-legi de Periodistes de Catalunya.

Payne, S. G. (1987). El régimen de Franco, 1936-1975. Madrid: Alianza.

Preston, P. (2005). Franco, caudillo de España. Madrid: RBA.

Sánchez Rada, J. (1996). Prensa: del Movimiento al Socialismo. 60 años de dirigismo informativo. Madrid: Fragua.

Sánchez-Tabernero, A. (1989). El Correo Español-El Pueblo Vasco y su entorno informativo (1910-1985). Pamplona: Servicio de publicaciones de la Universidad de Navarra.

Seoane, M. C., y Sueiro, S. (2004). Una historia de El País y del grupo Prisa. Barcelona: Plaza E Janés.

Seoane, M. C., y Saiz, M. D. (2007). Cuatro siglos de periodismo en España. De los avisos a los periódicos digitales. Madrid: Alianza.

Solà i Dachs, L. (1978). Història dels diaris en català. Barcelona 1879 1976. Barcelona: Edhasa.

Terrón Montero, J. (1981). La prensa en España durante el régimen de Franco. Un intento de análisis político. Madrid: CIS.

Tusell, J. (1988). La dictadura de Franco. Madrid: Alienza.

Vilarnovo, A., y Sánchez, J. F. (1994). Discurso, tipos de texto y comunicación. Pamplona: Eunsa.

Zugasti, R. (2007). La forja de una complicidad. Monarquía y prensa en la Transición española (1975-1978). Madrid: Fragua.

Zugasti, R. (2008). La prensa como actor colectivo en la transición española a la democracia. El ejemplo de los dos editoriales conjuntos de 1977. REPresentaciones. Periodismo, Comunicación y Sociedad, núm. 4, pp. 27-37. 